\title{
BMJ Open Maternal seafood intake and the risk of small for gestational age newborns: a case-control study in Spanish women
}

\author{
Carmen Amezcua-Prieto, 1,2,3 Juan Miguel Martínez-Galiano, 2,4 \\ Inmaculada Salcedo-Bellido, , ,2,3 Rocío Olmedo-Requena, ,2,3 \\ Aurora Bueno-Cavanillas, ${ }^{1,2,3}$ Miguel Delgado-Rodríguez ${ }^{2,4}$
}

To cite: Amezcua-Prieto C, Martínez-Galiano JM, SalcedoBellido I, et al. Maternal seafood intake and the risk of small for gestational age newborns: a case-control study in Spanish women. BMJ Open 2018;8:e020424. doi:10.1136/ bmjopen-2017-020424

- Prepublication history for this paper is available online. To view these files, please visit the journal online (http://dx.doi org/10.1136/bmjopen-2017020424).

Received 3 November 2017

Revised 14 June 2018

Accepted 11 July 2018

Check for updates

(C) Author(s) (or their employer(s)) 2018. Re-use permitted under CC BY-NC. No commercial re-use. See rights and permissions. Published by BMJ.

${ }^{1}$ Department of Preventive Medicine and Public Health, School of Medicine, University of Granada, Granada, Spain ${ }^{2}$ CIBER de Epidemiología y Salud Pública (CIBERESP, Spain),

Madrid, Spain

${ }^{3}$ Instituto de Investigación Biosanitaria de Granada (ibs Granada), Granada, Spain

${ }^{4}$ Department of Health Sciences, University of Jaen, Jaén, Spain

Correspondence to Dr Juan Miguel Martínez-

Galiano;

juanmimartinezg@hotmail.com

\section{ABSTRACT}

Objective To investigate the relationship between seafood consumption during pregnancy and the risk of delivering a small for gestational age (SGA) newborn.

Design This case-control study included women with SGA newborns and controls matched 1:1 for maternal age ( \pm 2 years) and hospital.

Setting Five hospitals in Eastern Andalusia, Spain.

Participants 518 pairs of pregnant Spanish women. The SGA group included women who delivered SGA newborns: SGA was defined as a birth weight below the 10th percentile of infants at a given gestational age. Controls were women who delivered newborns with adequate birth weights.

Interventions We collected data on demographic characteristics, socioeconomic status, toxic habits and diet. Midwives administered a 137-item Food Frequency Questionnaire.

Outcome measures We calculated quintiles of seafood intake and applied conditional logistic regression to estimate 0 Rs and $95 \%$ Cls.

Results Shellfish intake more than once/week yielded a significant protective effect against an SGA newborn (OR $0.25,95 \% \mathrm{Cl} 0.08$ to 0.76 , after adjusting for energy, educational level, smoking, prepregnancy body mass index, weight and a history of preterm or low birthweight newborn). The risk of an SGA newborn was lower among women who consumed $>29 \mathrm{~g} /$ day fish compared with women who consumed $\leq 8 \mathrm{~g}$ (adjusted OR $0.63,95 \% \mathrm{Cl}$ 0.41 to $0.98 ; p=0.025$ for a trend). Similarly, the risk of an SGA newborn was lower among women who consumed $>1 \mathrm{~g} /$ day of marine $\mathrm{n}-3$ polyunsaturated fatty acids compared with those who consumed $\leq 0.4 \mathrm{~g} /$ day (adjusted OR $0.58,95 \% \mathrm{Cl} 0.38$ to $0.90 ; \mathrm{p}=0.025$ for a trend). Conclusion An average seafood intake of at least $29 \mathrm{~g} /$ day during pregnancy, equivalent to $2-3$ servings/week, reduced the risk of an SGA newborn, compared with an average seafood intake of less than $8 \mathrm{~g} /$ day.

\section{INTRODUCTION}

Seafood is an important source of nutrients. It contains proteins, vitamin $\mathrm{D}$, minerals (iodine and selenium), and essential n-3 long-chain polyunsaturated fatty acids (n-3 LCPUFAs). There are three categories of seafood: lean

\section{Strengths and limitations of this study}

- The sample was representative of a reference population of healthy pregnant women with uncomplicated gestation periods who attended several Andalusian public hospitals.

- The case-control design allowed inclusion of a large number of small for gestational age (SGA) cases.

- We used previously established Spanish fetal growth curves to define the average size for gestational age, and we measured seafood consumption with a Food Frequency Questionnaire previously validated in the Spanish population.

- Spanish pregnant women had a relatively high fish intake (and shellfish intake) compared with pregnant women in other European countries.

- The control group was selected, based on 'density sampling', from the same hospitals that served the women with SGA newborns.

fish, fatty fish and shellfish (molluscs, crustaceans and cephalopods). ${ }^{1}$ It is well known that fatty fish and shellfish contain a higher content of n-3 LCPUFAs than lean fish. ${ }^{2-4}$

N-3 LCPUFAs, such as docosahexaenoic acid (DHA) and eicosapentaenoic acid (EPA), pass through the placental circulation. The intake of n-3 LCPUFAs during pregnancy affects fetal development and extends the gestation time. ${ }^{5}$ Moreover, n-3 LCPUFAs strongly affect fetal body composition. ${ }^{6}$ Furthermore, a study conducted in Hong Kong reported that an average maternal consumption of $450 \mathrm{~g}$ of seafood per week during pregnancy could increase the IQ in the offspring. ${ }^{7}$

On the other hand, seafood is a source of contaminants. It contains dioxins, polychlorinated biphenyls (PCBs) - which are mainly found in cod liver and fish oils ${ }^{8}$ and methylmercury $(\mathrm{MeHg})$. It was reported that low levels of $\mathrm{MeHg}$ are found in clams and mussels and high levels are found in tuna, sea bass, sea bream, monkfish, hake 
and octopus. ${ }^{9}$ In addition, $\mathrm{MeHg}$ is generally present in large oily fish, it crosses the placenta and it can alter fetal neurodevelopment. ${ }^{10}$ Based on those findings, the European Food Safety Authority Scientific Committee recommended that fish/seafood species with high mercury contents should be limited in the daily diet, in general, and particularly during the gestational period in pregnancy. ${ }^{11}$

The quantities of n-3 LCPUFAs and the concentrations of chemicals and toxic pollutants differ in different types of fish and shellfish. Consequently, there is some confusion about what amount of fish consumption would be suitable during pregnancy, to avoid damage from pollutants. ${ }^{12}$ Therefore, the Spanish Agency for Consumer Affairs, Food Safety and Nutrition offered advice on the types of fish that should be consumed by pregnant women, as follows: 'eat a wide variety of fish, but avoid contaminated species (eg, swordfish, fresh tuna, pike and shark)'. They also included a statement that advocated eating fish three to four times a week, primarily oily fish, such as anchovies, sardines or red mullet. ${ }^{1314}$

In addition, the European Food Safety Authority Scientific Committee recommended an intake of 1-4 servings of fish/week during pregnancy. ${ }^{11}$ Other international organisations have variously recommended: $\geq 1-2$ servings/week to provide nearly $200 \mathrm{mg}$ of n-3 LCPUFAs (eg, DHA and EPA) ${ }^{15-17} ; 2-3$ servings/week from the best choices' list, such as clams, cod, crab or shrimp; or 1 serving/week of the 'good choices list', such as monkfish and Spanish mackerel. ${ }^{18}$

Several longitudinal studies have evaluated the impact of maternal fish intake on the risk of small for gestational age (SGA) newborns. However, those studies have reported conflicting results; some reported positive effects, ${ }^{3} 1920$ some reported mixed effects ${ }^{121}$ and others reported negative ${ }^{122-25}$ or null effects. ${ }^{26-28}$ Such inconsistencies might arise from differences in the types of fish assessed, which would lead to different contents of pollutants and polyunsaturated n-3 fatty acids. ${ }^{21}$ Consequently, the relationships between fatty fish, lean fish or shellfish intake and the risk of having an SGA newborn remain unclear.

The present study aimed to determine how the consumption of different types of seafood during pregnancy affected the risk of having an SGA newborn.

\section{METHODS}

The study population included women who attended five hospitals in Eastern Andalusia (Spain): the University of Jaen Hospital (UJH), Ubeda Hospital, the University of Granada Hospitals (two centres) (UGH) and Poniente Hospital (PH). Taken together, these hospitals served 1.8 million people. The SGA and control groups were recruited from 15 May 2012 to 15 July 2015. .

We estimated the appropriate sample size, based on the results of a similar study. ${ }^{25}$ To detect a significant $(\mathrm{p}<0.05)$ OR of 0.6 between extreme quintiles with a statistical power of $80 \%$, we estimated that 447 pairs of cases and controls were required.

\section{SGA group}

Tables previously developed for the Spanish population ${ }^{29}$ classified SGA newborns as infants with birth weights below the 10th percentile of infants at the same gestational age. Mothers were eligible for the SGA group when they had delivered a single live SGA newborn with no congenital malformation during the study period; they had to reside in the referral area of the hospital and they had to have an adequate understanding of the Spanish language. Nineteen women declined participation. A total of 533 women were selected for the SGA case group, from the following hospitals: UJH $(n=79)$, UGH $(n=369)$, $\mathrm{UH}(\mathrm{n}=46)$ and $\mathrm{PH}(\mathrm{n}=39)$.

\section{Control group}

Within a week after including each woman in the SGA group, a woman of similar age at delivery ( \pm 2 years) was selected at the same hospital for the control group. Women eligible for the control group delivered a non-SGA newborn (birth weight above the 10th percentile), but otherwise had to meet the same inclusion criteria required for the SGA group (residence in the referral area of the hospital, single pregnancy with no malformation and an adequate understanding of Spanish). Sixtyfive women declined participation.

\section{Patient involvement}

Patients were informed of the study by providing a written document of the characteristics and objectives of the study. The health professionals involved in the recruitment and interview were available to clarify any doubts that might arise. Enrolled women were not involved in the recruitment of other participants. Personal identification data were not obtained; therefore, the results of this observational study could not be disseminated back to the individual participants.

\section{Data collection}

We used three sources of data. First, personal interviews were conducted by midwives within 2 days after delivery. Second, we reviewed clinical charts. Third, we reviewed prenatal care records.

We collected the following data: Mother's vital data, including age at pregnancy, race, education level, marital status, socioeconomic class and occupation; Obstetric history, including parity and abortions, previous adverse perinatal outcomes, and conditions during pregnancy (infections, pre-eclampsia, diabetes and other obstetric conditions); Birth weight measured (in grams) in the delivery room; drugs or medications, including prescribed drugs and over-the-counter medications; Social class, which included five main levels, ranging from I (the highest) to V (the lowest), according to the Spanish Society of Epidemiology classification system, ${ }^{30}$ which was close to that of the Black Report ${ }^{31}$; the Kessner Index, a measure of prenatal care utilisation (number of visits and 
date of first visit) ${ }^{32}$ and toxic habits, including alcohol consumption during and before pregnancy (assessed with a structured questionnaire, which queried the number and type of drinks taken on weekdays, weekends, including Friday evening and holidays, including holiday eves); and smoking during pregnancy. The same data collection procedures were performed for SGA and control groups.

\section{Dietary assessment}

The midwives provided the Food Frequency Questionnaire (FFQ) to women after birth. The completion and return of the questionnaire confirmed participation in the study. The baseline questionnaire included a 137-item FFQ previously validated in Spain, with open questions about the use of dietary supplements. ${ }^{33} 34$ The questions were based on typical portion sizes, and nine options described the frequency of intake in the previous year for each food item (range: never or almost never to $\geq 6$ times/ day). For each FFQ food item, we estimated (1) the average amount of food consumed (grams) multiplied by the intake frequency; (2) the average total energy intake and (3) the average intake of macro and micronutrients, based on the latest available information from Spanish food composition tables. ${ }^{35}{ }^{36}$ Additionally, we asked each woman whether she had modified her intake of any items on the FFQ due to her pregnancy (ie, lower, higher or unchanged intake).

Fish and shellfish were included in the FFQ as follows: lean fish (hake, whiting, grouper, flounder, monkfish, cod); fatty fish (anchovies, sardines, salmon, mackerel, fresh or frozen tuna, swordfish); salted and smoked fish (herring, salmon, anchovies); canned fish (canned tuna, canned fish in oil) and three different types of shellfish (1) bivalve molluscs: oysters, clams, mussels; (2) crustaceans: shrimp, prawns and (3) cephalopods: octopus, squid.

Seafood portion sizes were indicated in the FFQ and the midwives were trained to give examples of portion sizes, as follows: $100-150 \mathrm{~g}$ for lean fish, $130 \mathrm{~g}$ for fatty fish, $60 \mathrm{~g}$ for salted and smoked fish, $50 \mathrm{~g}$ for canned fish (equivalent to a small can), $100-150 \mathrm{~g}$ for molluscs (six specimens), $200 \mathrm{~g}$ for crustaceans (4-5 specimens) and $200 \mathrm{~g}$ for cephalopods. The FFQ also asked whether supplements of n-3 LCPUFAs were used; subjects included information about the product brand and the frequency of intake (range: never or almost never to $\geq 6$ times/day).

After computing the total energy intake, we excluded 15 matched pairs, due to unreliable dietary assessments (the total energy calculations indicated intakes above $4000 \mathrm{kcal} /$ day). Thus, 518 matched SGA and control pairs were included in the final analysis.

\section{Statistical analysis}

Quantitative variables are expressed as the mean, SD and range, and frequencies are expressed in absolute and relative terms. The intake frequencies were derived from the FFQ; each respondent indicated intakes for the different types of seafood as: never; 1-3 servings/month; 1 serving/week or $>1$ serving/week).

We used the residuals method to adjust food and nutrient intakes to the total energy intake, for the SGA and control groups in separates ways, as recommended previously. ${ }^{37}$ Nutrient intakes were stratified into quintiles, according to intakes observed in controls (which represent the general population); thus, the quintile bins used to stratify the n-3 fatty acid and fish intakes in the control group were applied to intakes reported in the SGA group.

We implemented conditional logistic regression models to calculate crude ORs (cORs) and adjusted ORs (aORs) with their 95\% CIs. The lowest quintile (Q1) was taken as the reference, and the main comparison was to the highest quintile (Q5). Trend analyses were performed with quintiles in logistic regression models, where the median intake for each quintile was introduced into the model. Intermediate variables were discarded, and to control for confounding variables, only variables that changed the diet coefficient by more than $10 \%$ were retained in the logistic models. A priori, we evaluated SGA risk factors in mothers that were related to diet (ie, tobacco use, pregestational body mass index (BMI), body weight, educational level, etc) as potential confounders. The model was adjusted for the following maternal factors: energy intake, educational level, smoking and pregestational BMI, and a previous preterm or low birthweight newborn. All p values are two tailed. Statistical significance was set at $\mathrm{p}<0.05$. We repeated the analysis after including supplemental products that contained n-3 LCPUFAs. We performed all analyses with Stata V.14.

\section{RESULTS}

Table 1 describes the characteristics of women included in the SGA and control groups. Marital status was different between the SGA and control groups. More women were married in the control group than in the SGA group $(p<0.036)$. Previous preterm deliveries and low birthweight newborns were more frequent in the SGA group than in the control group $(p<0.001)$. The SGA group included more women who smoked during pregnancy, more cases of pre-eclampsia and more women with intrauterine growth restriction during pregnancy than observed in the control group $(\mathrm{p}<0.001)$. The mean weight gain during pregnancy and the pregestational BMI were higher in the control group than in the SGA group $(\mathrm{p}<0.001)$.

Some items on the FFQ were modified by women during pregnancy. Fish intake was increased during pregnancy in $27.03 \%$ of women in the SGA group and in $24.13 \%$ of the controls. Conversely, fish intake was reduced during pregnancy in $6.37 \%$ of women in the SGA group and in $6.76 \%$ of controls $(\mathrm{p}=0.563)$. At least a $50 \%$ increase in fish intake was reported by $5.6 \%$ of women in the SGA group and by $4.8 \%$ of controls ( $\mathrm{p}=0.862$; data not shown in tables).

Table 2 shows the frequency of consumption of several types of seafood in the two groups. We observed a higher 
Table 1 Characteristics of the study population

\begin{tabular}{|c|c|c|c|}
\hline Characteristic & SGA group & Controls & $P$ values \\
\hline Marital status, $\mathrm{n}(\%)$ & & & 0.036 \\
\hline Single & $37(7.1)$ & $42(8.1)$ & \\
\hline Stable couple & $161(31.1)$ & $124(23.9)$ & \\
\hline Married & $320(61.8)$ & $352(68.0)$ & \\
\hline Education level, $n(\%)$ & & & 0.084 \\
\hline Primary & $112(21.6)$ & $93(17.9)$ & \\
\hline High school, not ended & $42(8.1)$ & $28(5.4)$ & \\
\hline High school & $185(35.7)$ & $190(36.7)$ & \\
\hline University & $179(34.6)$ & $207(40.0)$ & \\
\hline Previous preterm/low birthweight newborn, n (\%) & $64(12.4)$ & $26(5.0)$ & $<0.001$ \\
\hline Kessner Index (prenatal care), n (\%) & & & 0.737 \\
\hline Adequate & $259(50.0)$ & $253(48.8)$ & \\
\hline Intermediate & $185(35.7)$ & $182(35.2)$ & \\
\hline Inadequate & $74(14.3)$ & $83(16.0)$ & \\
\hline Smoking during pregnancy, $\mathrm{n}(\%)$ & $149(28.8)$ & $80(15.4)$ & $<0.001$ \\
\hline Pre-eclampsia, n (\%) & $46(8.9)$ & $11(2.1)$ & $<0.001$ \\
\hline Intrauterine growth retardation, $\mathrm{n}(\%)$ & $141(27.2)$ & $8(1.5)$ & $<0.001$ \\
\hline Weight gain during pregnancy (g/week), mean (SD) & $278(121)$ & $310(114)$ & $<0.001$ \\
\hline Pregestational body mass index, mean (SD) & $23.1(4.5)$ & $23.9(4.1)$ & $<0.001$ \\
\hline Alcohol intake (g/week), mean (SD) & $4.2(18.5)$ & $3.1(15.2)$ & 0.312 \\
\hline
\end{tabular}

SGA, small for gestational age.

intake of lean fish ( $>1$ serving/week) in the control group than in the SGA group. In the adjusted analysis, we found no significant association between the risk of SGA newborns and the intake of lean fish, fatty fish or salted fish. Nevertheless, more than once/week intakes of shellfish molluscs, such as clams, common cockles and mussels, yielded a lower risk of SGA newborns (aOR $0.25,95 \%$ CI 0.08 to 0.76 ), even though the intakes of this particular type of seafood were infrequent. We found that the occasional intake of shellfish, cephalopods, squid and octopus conferred a slight protective effect against an SGA birth (no more than 3 servings/ month; aOR $0.62,95 \%$ CI 0.44 to 0.87 ), but this association was not observed with more frequent intakes (ie, there was no trend). We also found that canned fish intake $(>1 /$ week) had an overall protective effect, and this association was similar in the multivariable analysis, although not significant (aOR 0.64, 95\% CI 0.37 to 1.13). Thus, canned fish with oil (the typical intake) was unrelated to the risk of an SGA newborn.

Table 3 shows the associations (ORs) between the risk of an SGA newborn and different daily intakes of seafood and marine $n-3$ fatty acids ( $\mathrm{g}$ /day), stratified into quintiles. We found that a higher daily intake of seafood or marine n-3 fatty acids yielded significant protection against an SGA newborn. The OR of delivering an SGA newborn was lower with seafood intakes of $>29 \mathrm{~g} /$ day $(\mathrm{Q} 5$; aOR $0.63,95 \%$ CI 0.41 to 0.98 ) compared with intakes of $\leq 8 \mathrm{~g} /$ day ( 1 ; $\mathrm{p}=0.025$ for this trend). Moreover, the risk of having an
SGA newborn was lower among women in Q5, with high daily intakes of marine $\mathrm{n}-3$ fatty acids $(>1 \mathrm{~g} /$ day; aOR 0.58 , $95 \%$ CI 0.38 to 0.90$)$ than in the Q1 group $(\leq 0.4 \mathrm{~g} /$ day; $\mathrm{p}=0.025$ for the trend).

We also investigated whether the intake of n-3 LCPUFA supplements was related to the risk of an SGA newborn. We found that $8.7 \%$ of women in the SGA group and $6.2 \%$ of controls used these supplements. Among these, all but one woman used the same pharmaceutical brand (Natalben). The average daily intake was $200 \mathrm{mg}$. The cOR was 1.46 (95\% CI 0.91 to 2.37), and it remained unaltered after adjusting for confounders (aOR 1.51, 95\% CI 0.90 to 2.52). The inclusion of these supplements in the multivariable analyses of fish and marine n-3 fatty acid intakes did not change the previous results.

\section{DISCUSSION}

Our results demonstrated that the risk of having an SGA newborn was not consistently associated with the intakes of specific types of seafood (lean fish, fatty fish and shellfish) during pregnancy, when these types were addressed separately. However, when we considered the entire seafood intake during pregnancy, women in the highest quintile (Q5) had a lower risk of an SGA newborn than those in the lowest quintile (Q1). This result was reinforced, when we analysed the total intake of marine n-3 fatty acids. 
Table 2 Frequency of maternal intake of different seafood and ORs for the risk of an SGA infant

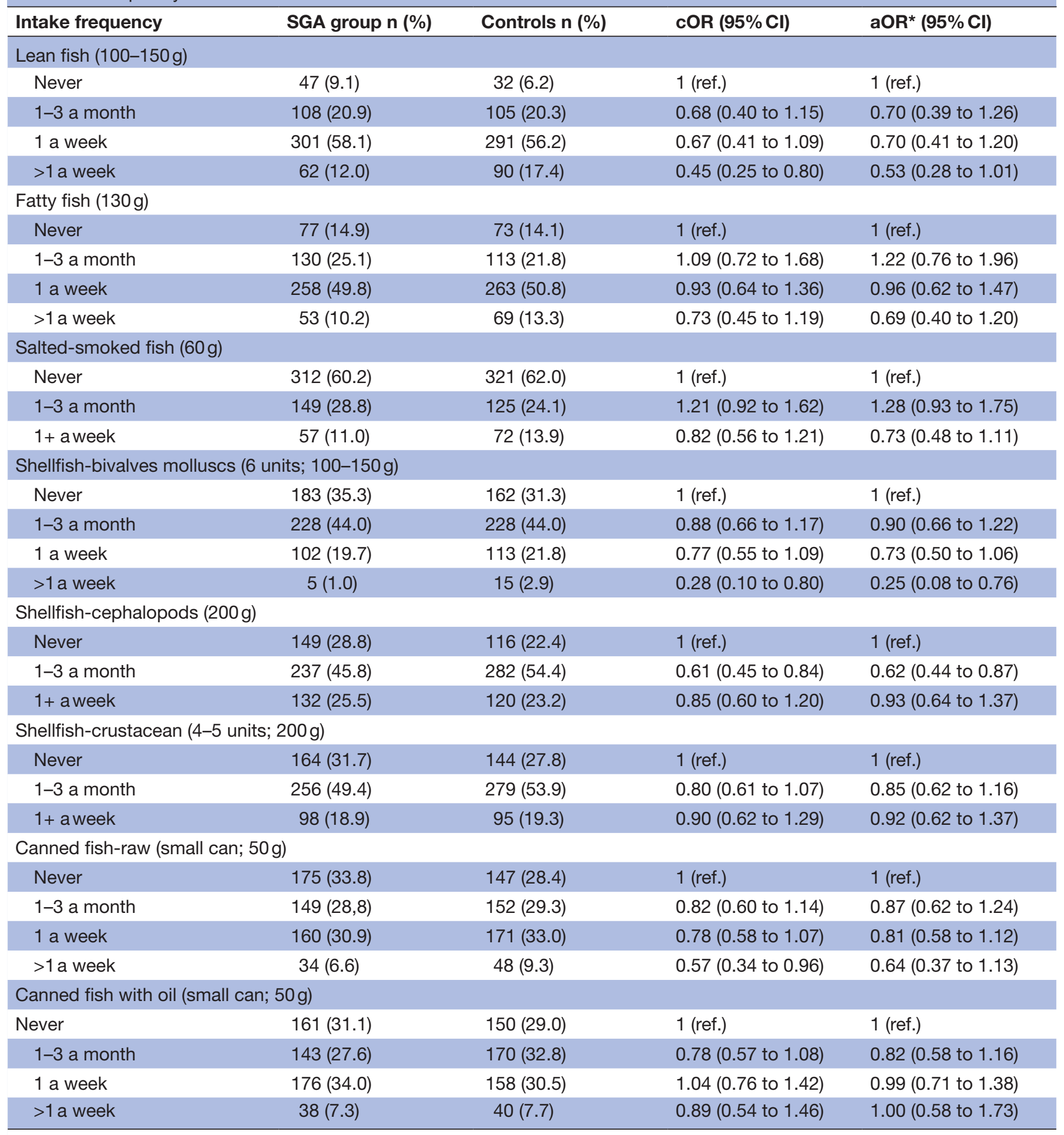

*Adjusted for energy intake, educational level, smoking, pregestational BMI and previous preterm or low birthweight newborn. aOR, adjusted OR; BMI, body mass index; cOR, crude OR; SGA, small for gestational age.

One of the strengths of this study was the low likelihood that biases might have affected our findings. A selection bias was unlikely, because the number of women who refused to participate was rather small (3\% for the SGA group and $11 \%$ for the control group). Moreover, the FFQ used to measure, the diet was previously validated. ${ }^{33}$ This tool was acceptable, but some misclassification bias could not be ruled out. Nevertheless, the likelihood of a differential bias was low, because currently, there are no special recommendations on seafood intake for women with intrauterine growth retardation, low weight gain during pregnancy, or signs of an SGA infant detected during obstetric explorations (mainly ultrasonic scans). Another strength was that the controls were density matched to women in the SGA 
Table 3 Associations between quintiles of daily seafood and marine $n-3$ fatty acids intakes and the birth of an SGA infant

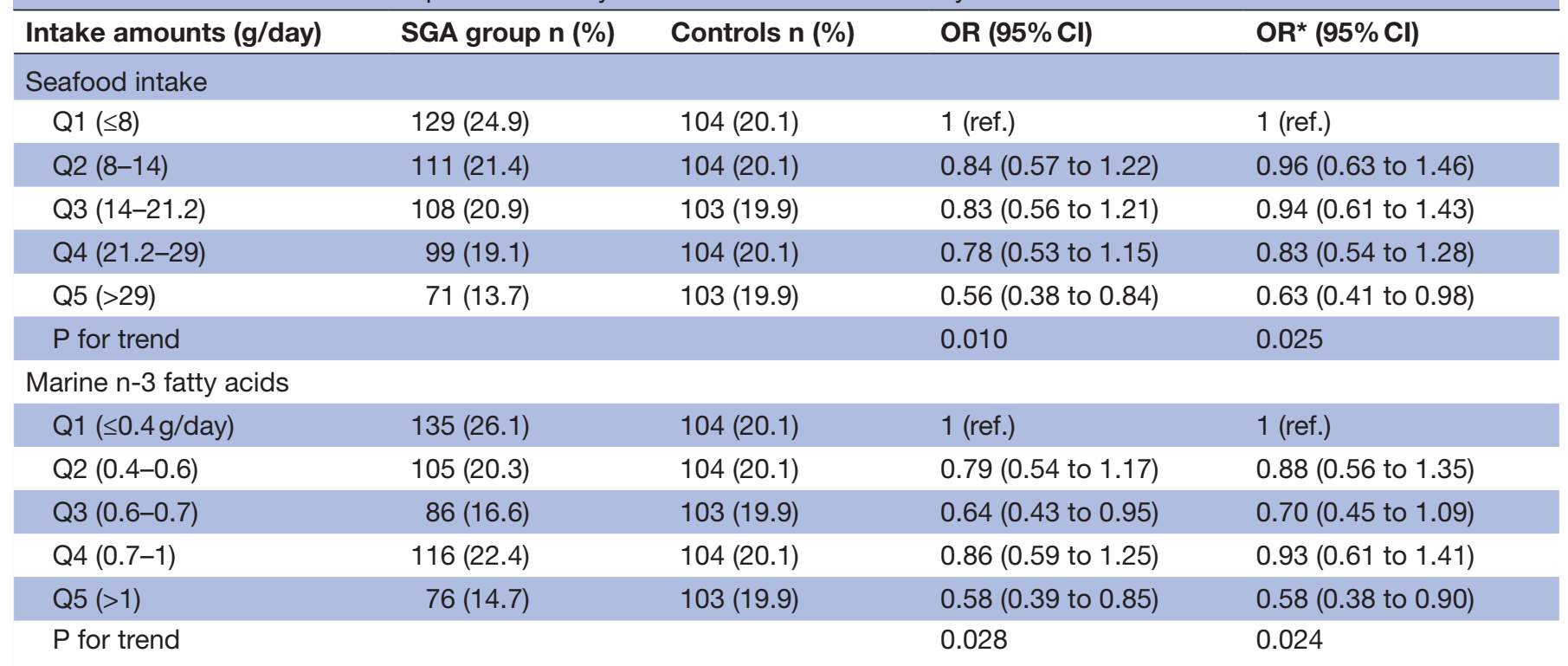

*Adjusted for energy intake, educational level, smoking, pregestational BMI and previous preterm or low birthweight newborn.

BMI, body mass index; SGA, small for gestational age.

group; thus, seasonal influences on the responses to the FFQ were unlikely to affect our results, and a cohort effect on diet was avoided (younger women consumed a Westernised diet more frequently than older women). Moreover, age matching between cases and controls ensured that the reported preference for seafood among older women ${ }^{38} 39$ would not alter the results. Therefore, any potential misclassification bias was likely to be non-differential, which would cause an underestimation of the strength of an association, that is, when an association was observed in the data, the actual association was likely to be higher than that calculated. We also reduced biases due to confounding factors by collecting data on the most important determinants of SGA and considering them in multivariable analyses. However, this study also had some limitations. First, it was unlikely that our results were completely free of biases, and residual confounding could not be totally ruled out. Moreover, although we found that the total seafood intake and marine n-3 fatty acid intake were associated with a lower probability of delivering an SGA newborn, we could not demonstrate causality. However, some causality items were fulfilled, including, the strength of the association and consistency. Finally, our study was limited by the inability to adjust for environmental contaminants in the seafood.

One advantage of our study, which increased our statistical power, was that the Spanish population has a relatively high seafood intake, and a wide variety of species are typically included in the Spanish diet. ${ }^{40}$ Additionally, we found that, in our sample, women were more likely to increase, rather than decrease, fish intake during pregnancy. Nevertheless, in our study, a substantial proportion of women (about 30\%) displayed little (1-3 servings/ month) or no seafood intake, which allowed us to assess whether dietary fish was associated with a lower risk of an SGA newborn. The use of n-3 LCPUFA supplements was scarce in our population (200 mg/day in Q2), much lower than the amounts consumed in the diet $(>460 \mathrm{mg} /$ day in Q2). It has been pointed out that supplements taken in the last half of the gestation period could provide a modest increase in measures at birth (eg, a higher birth weight) and reduce the probability of delivering before week $34 .^{542}$ Nevertheless, those reports remarked that most randomised trials of prenatal n-3 LCPUFA supplementation had been conducted in high-income countries, and therefore, the findings were not generalisable to populations in low-income and middle-income settings.

Several previous studies have analysed the impact of seafood intake on the risk of delivering SGA newborns. Most studies were conducted with European cohorts, ${ }^{13} 232627$ but two were conducted in Spanish Mediterranean populations. ${ }^{20}$ The sample sizes of those studies ranged from 657 women $^{21}$ to 62099 women. $^{23}$ In general, almost all studies measured seafood intake with a validated FFQ but the responses were collected at different times during pregnancy, that is, at the beginning of pregnancy, ${ }^{1}$ at mid-pregnancy 192123262743 and at birth ${ }^{22} 25$; the latter studies were conducted in Italian ${ }^{25}$ and Japanese women. ${ }^{22}$ However, many of those studies provided inconsistent results. In the present study, we collected all FFQ responses at birth.

The reported associations between the risk of an SGA newborn and seafood intake appeared to depend on the FFQ collection period. When the FFQ was completed at the beginning of pregnancy, for example, Halldorsson et $a l^{3}$ found that, among 44824 Danish women, the risk of an SGA newborn was positively associated with more than 4 servings of fatty fish/month. Similarly, in a cross-sectional study of Indian women with a low birthweight prevalence of $20 \%$, weekly fish consumption increased the risk of having a low birthweight infant by 26\%. ${ }^{19}$ The Omega Study, conducted in Seattle Washington, showed that, in the 
pregnancy cohort, higher intakes of shellfish (more than 1 serving/week) and lean fish (more than 1 serving/week) were associated with a higher risk of low birth weight. ${ }^{43}$

Conversely, when the FFQ was completed at mid-pregnancy, a protective effect was found with seafood intake. One study in 62099 Norwegian women showed that the relative risk of delivering a low birthweight baby $(<2500 \mathrm{~g})$ in full-term pregnancies was significantly lower in women who consumed $>60 \mathrm{~g} /$ day of seafood than in women who consumed $\leq 5 \mathrm{~g} /$ day of seafood. ${ }^{23}$ Finally, an Italian retrospective case-control study ( $\mathrm{n}=555$ women) and a Turkish study ( $\mathrm{n}=553$ healthy pregnant women), reported that eating more fish reduced the odds of delivering an SGA newborn. ${ }^{25}{ }^{44}$ However, those studies were limited by small numbers of SGA cases.

In our study, intakes of 2-3 seafood servings/week were observed two times as frequently in the control group as in the SGA group. This finding was supported by data from 19 European birth cohort studies, which showed that the average birth weight was $15.2 \mathrm{~g}$ higher (95\% CI 8.9 to $21.5 \mathrm{~g}$ ) among women with a high fish intake during pregnancy ( $>3$ servings/week) than among women with low fish intakes $(<1$ serving/week), independent of gestational age. ${ }^{12}$ Recently, a meta-analysis of the same data investigated fish intake effects on the growth rate in infancy. ${ }^{24}$ They found that, among mothers with high fish intakes ( $>$ 3 serving/week) during pregnancy, the offspring BMI values were higher from infancy through middle childhood compared with offspring from mothers with low fish intakes ( $\leq 3$ servings/week); this association was slightly stronger in female than in male newborns.

Other previous studies did not find any association between fish intake and the risk of an SGA newborn. This occurred in the study by Heppe $e t a l^{27}$ in a sample of 3380 pregnant women from Rotterdam, characterised by a low fish intake (median fish consumption, $75 \mathrm{~g}$ /week). Additionally, Drouillet $e t a t^{26}$ found no association between a seafood intake of $>2$ servings/week before pregnancy and the risk of an SGA newborn in a sample of 1805 women from the French Eden mother-child cohort. However, among women with BMIs $\geq 25 \mathrm{~kg} / \mathrm{m}^{2}$ in that cohort, women with pregestational seafood intakes of $<5$ servings/month had a threefold higher risk of an SGA newborn than women with intakes $\geq 9$ servings / month.

Studies on specific types of seafood and the risk of SGA newborns have produced controversial results. For example, among Spanish women in Barcelona, canned tuna or crustacean intakes $>1$ serving/week increased the risk of SGA newborns. ${ }^{20}$ Our results were inconsistent with the results of that study. In the Pelagie Cohort study, Guldner $e t a l^{1}$ studied a sample of 2398 French pregnant women. They found that 2 servings/week of fish and shellfish protected against SGA newborns; however, when considered individually, the effects were contradictory: fish reduced the risk, and shellfish increased the risk of SGA newborns. In our study, women who consumed more than 1 serving/week of bivalve molluscs had a lower risk of SGA newborns than women who consumed less than 1 serving/week. This finding might be explained by the rich content of vitamin $\mathrm{B}_{12}$ and fatty acids and the low percentage of heavy metals in molluscs. ${ }^{45}$ In addition, in the present case-control study, we observed that controls consumed more fatty fish, cephalopod shellfish and canned fish during pregnancy than women with SGA newborns.

Some of the observed discrepancies between studies might be due to the different fish species considered. We did not find a consistent pattern of association between the risk of SGA newborns and the isolated fish types, except for bivalve molluscs. However, a protective effect was evident for seafood consumption, in general. This phenomenon was previously described in other studies on seafood consumption in pregnancy ${ }^{1}$ and in studies that analysed the effect of a Mediterranean diet on cardiovascular risk: the overall diet pattern, but not any individual food, showed a preventive effect. ${ }^{46}$ We must consider that, in Spain, seafood intake is high and varied. Thus, an alternative type of seafood might compensate for low intake of a specific type of seafood, by contributing n3-fatty acids to the diet; for example, women with a low intake of molluscs might have a high intake of fatty fish and vice versa. This situation suggested that, instead of recommending the consumption of specific types of seafood during pregnancy, we should consider recommending all seafood, except known contaminated species (ie, swordfish, fresh tuna, pike and shark). Thus, pregnant women should consume 3-4 servings of seafood (fish and shellfish)/week, as recommended, ${ }^{13}$ to protect against the risk of SGA newborns.

In summary, we found that an intake of at least $29 \mathrm{~g} /$ day of seafood, or at least $1 \mathrm{~g}$ /day of n3-fatty acids, was observed nearly two times as frequently in controls than in women with SGA newborns. This finding suggested that an intake of 3-4 seafood servings/week, according to recommendations, could reduce the frequency of SGA newborns. In our sample, less than $20 \%$ of pregnant women followed this recommendation; therefore, a nutritional educational intervention is required to target the general population, and specifically, pregnant women.

Contributors MD-R conceived and designed the study, analysed the data and discussed and approved the final version of the article. JMMG conceived and designed the study, coordinated the data collection, and discussed and approved the final version of the article. AB-C analysed the data, discussed the results and approved the final version of the article. IS-B coordinated the data collection, discussed the results and approved the final version of the article. $\mathrm{R} 0-\mathrm{R}$ coordinated the data collection, discussed the results and approved the final version of the article. CA-P drafted the article, discussed the results and approved the final version of the article.

Funding The National Institute of Health Carlos III (PI11/02199) supported this work.

Competing interests None declared.

Patient consent Obtained.

Ethics approval The ethics committees of the included hospitals authorised this study.

Provenance and peer review Not commissioned; externally peer reviewed.

Data sharing statement № additional data are available.

Open access This is an open access article distributed in accordance with the Creative Commons Attribution Non Commercial (CC BY-NC 4.0) license, which 
permits others to distribute, remix, adapt, build upon this work non-commercially, and license their derivative works on different terms, provided the original work is properly cited, appropriate credit is given, any changes made indicated, and the use is non-commercial. See: http://creativecommons.org/licenses/by-nc/4.0/.

\section{REFERENCES}

1. Guldner L, Monfort C, Rouget F, et al. Maternal fish and shellfish intake and pregnancy outcomes: a prospective cohort study in Brittany, France. Environ Health 2007;6:33.

2. Oken E, Østerdal ML, Gillman MW, et al. Associations of maternal fish intake during pregnancy and breastfeeding duration with attainment of developmental milestones in early childhood: a study from the Danish National Birth Cohort. Am J Clin Nutr 2008;88:789-96.

3. Halldorsson TI, Meltzer HM, Thorsdottir I, et al. Is high consumption of fatty fish during pregnancy a risk factor for fetal growth retardation? A study of 44,824 Danish pregnant women. Am J Epidemiol 2007;166:687-96.

4. Rodellar S, Fontcuberta M, Arqués JF, et al. Mercury and methylmercury intake estimation due to seafood products for the Catalonian population (Spain). Food Addit Contam Part A Chem Anal Control Expo Risk Assess 2010;27:29-35.

5. Imhoff-Kunsch B, Briggs V, Goldenberg T, et al. Effect of n-3 long-chain polyunsaturated fatty acid intake during pregnancy on maternal, infant, and child health outcomes: a systematic review. Paediatr Perinat Epidemiol 2012;26(Suppl 1):91-107.

6. Pereira-da-Silva L, Cabo C, Moreira AC, et al. The effect of long-chain polyunsaturated fatty acids intake during pregnancy on adiposity of healthy full-term offspring at birth. $J$ Perinatol 2015;35:177-80.

7. Chen MY, Wong WW, Chung SW, et al. Quantitative risk-benefit analysis of fish consumption for women of child-bearing age in Hong Kong. Food Addit Contam Part A Chem Anal Control Expo Risk Assess 2014;31:48-53.

8. Blanco L, Martínez A, Ferreira M, et al. Polychlorinated dibenzo-pdioxins and dibenzofurans (PCDD/Fs) and dioxin-like polychlorinated biphenyls (dl-PCBs) in fish, seafood products and fish oil in Spain. Food Addit Contam Part B Surveill 2013;6:218-30.

9. Jacobs S, Sioen I, Jacxsens L, et al. Risk assessment of methylmercury in five European countries considering the national seafood consumption patterns. Food Chem Toxicol 2017;104:26-34.

10. Vejrup K, Schjølberg S, Knutsen HK, et al. Prenatal methylmercury exposure and language delay at three years of age in the Norwegian Mother and Child Cohort Study. Environ Int 2016;92-93:63-9.

11. Statement on the benefits of fish/seafood consumption compared to the risks of methylmercury in fish/seafood. EFSA Journal 2015;13:3982.

12. Leventakou V, Roumeliotaki T, Martinez D, et al. Fish intake during pregnancy, fetal growth, and gestational length in 19 European birth cohort studies. Am J Clin Nutr 2014;99:506-16.

13. Spanish Agency for Consumer Affairs, Food Safety and Nutrition (AECOSAN). Safety food during pregnancy, 2014. http://www. aecosan.msssi.gob.es/AECOSAN/web/para el_consumidor/ ampliacion/alimentacion_segura_embarazo.htm

14. Spanish Agency for Consumer Affairs, Food Safety and Nutrition (AECOSAN). Seafood intake recommendations for sensible population to mercury. 2014 http://www.aecosan.msssi.gob.es/ AECOSAN/web/para_el_consumidor/ampliacion/mercurio_pescado. htm

15. Koletzko B, Cetin I, Brenna JT, et al. Dietary fat intakes for pregnant and lactating women. Br J Nutr 2007;98:873-7.

16. FAO Food and Nutrition Paper. Fats and fatty acids in human nutrition: Report of an expert consultation, 2010.

17. Scientific Opinion on the Tolerable Upper Intake Level of eicosapentaenoic acid (EPA), docosahexaenoic acid (DHA) and docosapentaenoic acid (DPA). EFSA Journal 2012;10:2815.

18. FDA and EPA. Eating Fish: What Pregnant Women and Parents Should Know. 2017 https://www.fda.gov/downloads/Food/Foodborn elllnessContaminants/Metals/UCM537120.pdf

19. Malhotra N, Upadhyay RP, Bhilwar M, et al. The role of maternal diet and iron-folic acid supplements in influencing birth weight: evidence from India's National Family Health Survey. J Trop Pediatr 2014;60:454-60.

20. Mendez MA, Plana E, Guxens M, et al. Seafood consumption in pregnancy and infant size at birth: results from a prospective Spanish cohort. J Epidemiol Community Health 2010;64:216-22.

21. Ramón R, Ballester F, Aguinagalde X, et al. Fish consumption during pregnancy, prenatal mercury exposure, and anthropometric measures at birth in a prospective mother-infant cohort study in Spain. Am J Clin Nutr 2009;90:1047-55.
22. Okubo H, Miyake Y, Sasaki S, et al. Maternal dietary patterns in pregnancy and fetal growth in Japan: the Osaka Maternal and Child Health Study. Br J Nutr 2012;107:1526-33.

23. Brantsæter AL, Birgisdottir BE, Meltzer HM, et al. Maternal seafood consumption and infant birth weight, length and head circumference in the Norwegian Mother and Child Cohort Study. Br J Nutr 2012;107:436-44.

24. Stratakis N, Roumeliotaki T, Oken E, et al. Fish Intake in Pregnancy and Child Growth: A Pooled Analysis of 15 European and US Birth Cohorts. JAMA Pediatr 2016;170:381-90.

25. Ricci E, Chiaffarino F, Cipriani S, et al. Diet in pregnancy and risk of small for gestational age birth: results from a retrospective casecontrol study in Italy. Matern Child Nutr 2010;6:297-305.

26. Drouillet $P$, Kaminski M, De Lauzon-Guillain B, et al. Association between maternal seafood consumption before pregnancy and fetal growth: evidence for an association in overweight women. The EDEN mother-child cohort. Paediatr Perinat Epidemiol 2009;23:76-86.

27. Heppe DH, Steegers EA, Timmermans S, et al. Maternal fish consumption, fetal growth and the risks of neonatal complications: the Generation R Study. Br J Nutr 2011;105:938-49.

28. Saccone G, Saccone I, Berghella V. Omega-3 long-chain polyunsaturated fatty acids and fish oil supplementation during pregnancy: which evidence? J Matern Fetal Neonatal Med 2016;29:2389-97.

29. Delgado Beltrán P, Melchor Marcos JC, Rodríguez-Alarcón Gómez $J$, et al. [The fetal development curves of newborn infants in the Hospital de Cruces (Vizcaya). II. Length, head circumference and ponderal index]. An Esp Pediatr 1996;44:55-9.

30. Álvarez-Dardet C, Alonso J, Domingo A, et al. La Medición de la Clase Social en Ciencias de la Salud, Informe de un Grupo de Trabajo de la Sociedad Española de Epidemiología: SG Editores, 1995.

31. Black D, Townsend P. Inequalities in health. Reprint. Harmondsworth: Penguin, 1983.

32. Kessner DM, Singer J, Kalk CE, et al. Infant Death: An Analysis by Maternal Risk and Health Care. Washington, DC: Institute of Medicine and National Academy of Sciences, 1973.

33. Martin-Moreno JM, Boyle P, Gorgojo L, et al. Development and validation of a food frequency questionnaire in Spain. Int $J$ Epidemiol 1993;22:512-9.

34. Fernández-Ballart JD, Piñol JL, Zazpe I, et al. Relative validity of a semi-quantitative food-frequency questionnaire in an elderly Mediterranean population of Spain. Br J Nutr 2010;103:1808-16.

35. Mataix Verdú J. Spanish food composition tables (Tabla de composición de alimentos españoleS). 4th edn. Granada: Spain, 2003.

36. Moreiras O, Carbajal A, Cabrera L, et al. Spanish food composition tables (Tablas de composición de alimentos). 7th edn, 2003.

37. Willett W, Stampfer MJ. Implications of total energy intake for epidemiologic analysis. In: Willett W, ed. Nutritional Epidemiology. 2nd edn. New York: Oxford University Press, 1998:273-301. pp.

38. Rehm CD, Peñalvo JL, Afshin A, et al. Dietary Intake Among US Adults, 1999-2012. JAMA 2016;315:2542-53.

39. Meyer BJ. Australians are not Meeting the Recommended Intakes for Omega-3 Long Chain Polyunsaturated Fatty Acids: Results of an Analysis from the 2011-2012 National Nutrition and Physical Activity Survey. Nutrients 2016;8:111

40. Micha R, Khatibzadeh S, Shi P, et al. Global, regional and national consumption of major food groups in 1990 and 2010: a systematic analysis including 266 country-specific nutrition surveys worldwide. BMJ Open 2015;5:008705.

41. Villar-Vidal M, Amiano P, Rodríguez-Bernal C, et al. Compliance of nutritional recommendations of Spanish pregnant women according to sociodemographic and lifestyle characteristics: a cohort study. Nutr Hosp 2015;31:1803-12.

42. Chen B, Ji X, Zhang L, et al. Fish oil supplementation improves pregnancy outcomes and size of the newborn: a meta-analysis of 21 randomized controlled trials. J Matern Fetal Neonatal Med 2016;29:2017-27.

43. Mohanty AF, Thompson ML, Burbacher TM, et al. Periconceptional Seafood Intake and Fetal Growth. Paediatr Perinat Epidemiol 2015;29:376-87.

44. Canda MT, Sezer O, Demir N. An audit of seafood consumption awareness during pregnancy and its association with maternal and fetal outcomes in a Turkish population. J Obstet Gynaecol 2011;31:293-7.

45. Rittenschober D, Nowak V, Charrondiere UR. Review of availability of food composition data for fish and shellfish. Food Chem 2013;141:4303-10.

46. Trichopoulou A, Costacou T, Bamia C, et al. Adherence to a Mediterranean diet and survival in a Greek population. N Engl J Med 2003;348:2599-608. 
Corrections: Maternal seafood intake and the risk of small

for gestational age newborns: a case-control study in

Spanish women

Amezcua-Prieto C, Martínez-Galiano JM, Salcedo-Bellido I, et al. Maternal seafood intake and the risk of small for gestational age newborns: a case-control study in Spanish women BMJ Open 2018;8:e020424. doi: 10.1136/bmjopen-2017-020424.

This article was previously published with some errors.

In Table 3 in the quantity of quintiles of seafood intake (in grams), where it says:

Q1 (s8); Q2 (8-14); Q3 (14-21.2); Q4 (21.2-29); Q5 (>29)

It should be:

Q1 (s56); Q2 (56.1-74.0); Q3 (74.1-92.6); Q4 (92.7-121); Q5 (>121)

Considering this correction, some sections changes from the original published manuscript:

In the Abstract, in the result section, the sentence:

The risk of an SGA newborn was lower among women who consumed $>29 \mathrm{~g} /$ day fish compared with women who consumed $\leq 8 \mathrm{~g}$ (adjusted OR $0.63,95 \%$ CI 0.41 to 0.98 ; $\mathrm{p}=0.025$ for a trend).

Should be:

The risk of an SGA newborn was lower among women who consumed $>121 \mathrm{~g} /$ day fish compared with women who consumed $\leq 56 \mathrm{~g}$ (adjusted OR $0.63,95 \%$ CI 0.41 to 0.98 ; $\mathrm{p}=0.025$ for a trend).

In Abstract, in the conclusion, the sentence:

An average seafood intake of at least $29 \mathrm{~g}$ / day during pregnancy, equivalent to 2-3 servings/week, reduced the risk of an SGA newborn, compared with an average seafood intake of less than $8 \mathrm{~g} /$ day.

Should be:

An average seafood intake of at least $121 \mathrm{~g}$ /day during pregnancy, equivalent to 3-4 servings/week, reduced the risk of an SGA newborn, compared with an average seafood intake of less than $56 \mathrm{~g} /$ day.

In the result section of the manuscript, in page 4, the sentence:

The OR of delivering an SGA newborn was lower with seafood intakes of $>29 \mathrm{~g} /$ day (Q5; aOR $0.63,95 \%$ CI 0.41 to 0.98 ) compared with intakes of $\leq 8 \mathrm{~g}$ /day (Q1; $\mathrm{p}=0.025$ for this trend).

Should be:

The OR of delivering an SGA newborn was lower with seafood intakes of $>121 \mathrm{~g} /$ day (Q5; aOR 0.63, 95\% CI 0.41 to 0.98 ) compared with intakes of $\leq 56 \mathrm{~g} /$ day (Q1; $\mathrm{p}=0.025$ for this trend).

In the conclusion:

In summary, we found that an intake of at least $29 \mathrm{~g} /$ day of seafood, or at least $1 \mathrm{~g} /$ day of n3-fatty acids, was observed nearly two times as frequently in controls than in women with SGA newborns. 
Should be:

In summary, we found that an intake of at least $121 \mathrm{~g} /$ day of seafood, or at least $1 \mathrm{~g}$ / day of n3-fatty acids, was observed nearly two times as frequently in controls than in women with SGA newborns.

Open access This is an open access article distributed in accordance with the Creative Commons Attribution Non Commercial (CC BY-NC 4.0) license, which permits others to distribute, remix, adapt, build upon this work non-commercially, and license their derivative works on different terms, provided the original work is properly cited, appropriate credit is given, any changes made indicated, and the use is non-commercial. See: http://creativecommons.org/licenses/by-nc/4.0/.

(c) Author(s) (or their employer(s)) 2018. Re-use permitted under CC BY-NC. No commercial re-use. See rights and permissions. Published by BMJ.

BMJ Open 2018;8:e020424corr1. doi:10.1136/bmjopen-2017-020424corr1

(D) Check for updates 